\title{
Engelli Çocuğa Sahip Ebeveynlerin Duygusal Sağırlık ve Psikolojik İyi Oluş Düzeylerinin İncelenmesi
}

\author{
Öğr. Gör. Cem TÜMLÜ* \\ Anadolu Üniversitesi, Engelliler Araștırma Enstitüsü, Yunus Emre Yerleşkesi, \\ Tepebaşı / Eskişehir / Türkiye, cemtumlu@anadolu.edu.tr, ORCID: 0000-0001-5288-7836
}

\author{
Doç. Dr. Bahtiyar ERASLAN ÇAPAN \\ Anadolu Üniversitesi, Eğitim Fakültesi, Yunus Emre Yerleşkesi, Tepebaşı / Eskişehir / Türkiye, \\ beraslan@anadolu.edu.tr, ORCID: 0000-0001-5000-7321
}

\section{$\ddot{\mathbf{O} z}$}

$\mathrm{Bu}$ çalışma, engelli ve normal gelişim gösteren çocuğa sahip ebeveynlerin "duygusal sağırlık” özellikleri ve "psikolojik iyi oluşları” arasındaki ilişkiyi belirlemek amacıyla yapılmıştır. Araştırmanın çalışma grubunu, 2017 bahar döneminde Anadolu Üniversitesi Engelliler Araştırma Enstitüsü'nde eğitimlerine devam eden engelli çocukların 161 ebeveyni ve Eskişehir' de anasınıfına devam eden normal gelişim gösteren çocukların 165 ebeveyni olmak üzere 326 anne-baba oluşturmaktadır. Veri toplamada Kişisel Bilgi Formu, Toronto Aleksitimi Ölçeği (TAÖ-20) ve Psikolojik İyi Oluş Ölçeği (Flourishing Scale-PİOÖ) kullanılmıştır. Verilerin analizinde frekans ve yüzdelik değerleri, tek yönlü MANOVA ve pearson momentler çarpımı korelasyon katsayısı kullanılmıştır. Analiz sonucunda duygusal sağırlık yaygınlığı engelli çocuğa sahip ebeveynlerde normal gelişim gösteren çocuğa sahip ebeveynlere göre daha yüksek bulunmuştur. Bunun yanında, engelli ve normal gelişim gösteren çocuğa sahip

* Sorumlu Yazar. Tel: +90 90 (222) $3350580 / 4396$

(C) 2018 Kalem Eğitim ve Sağlık Hizmetleri Vakfı. Bütün Hakları Saklıdır. 
ebeveynlerin duygularını tanımada zorluk $(\mathrm{F}=18.611, p<.05, \eta 2=.054)$ ve duygularını ifade etmede zorluk $(\mathrm{F}=19.249, p<.05, \eta 2=.056)$ duygusal sağırlı özellikleri ve psikolojik iyi oluşları $(\mathrm{F}=7.779, p<.05, \eta 2=.023)$ arasında istatistiksel olarak anlamlı bir farklılık olduğu bulunmuştur. Ancak bu iki grup arasında, dışsal odaklı düşünce duygusal sağırlık özelliği arasında anlamlı bir fark bulunmamıştır. Ayrıca, engelli ve normal çocuğa sahip annelerin duygusal sağırlık özellikleri yükselirken psikolojik iyi oluşlarının azaldığı bulunmuş, babalarda ise istatistiksel olarak anlamlı bir ilişki belirlenmemiştir. Engelli çocuğa sahip ebeveynler, karşılaştıkları psikolojik zorlanmalar nedeniyle duygusal sağıllık özellikleri gösterebileceği ve psikolojik iyi oluşlarının düşebileceği söylenebilir.

Anahtar Kelimeler: Duygusal sağırlık; Aleksitimi; Psikolojik iyi oluş; Engelli çocuğa sahip ebeveynler; Duyguları ifade etme.

\title{
An Investigation of the Alexithymia Levels and the Flourishing Levels of Parents with Disabled Children
}

\begin{abstract}
The purpose of this study is to investigate the relationship between the alexithymia levels and the flourishing levels of parents having children with a normal development and of those having disabled children. The study group consists of 326 parents. Of the participants, 161 were parents of disabled children attending Anadolu University Research Institute for Individuals with Disabilities in the spring semester of 2017 and 165 were parents of children with a normal development attending nursery classes of schools affiliated with the Republic of Turkey Ministry of National Education. The research data were collected through personal information form, Toronto Alexithymia Scale (TAS-20) and Flourishing Scale (FS). The data were analyzed based on frequency and percentage values, one-way MANOVA, and Pearson's product-moment correlation coefficient statistics. The analysis results indicate that alexithymia is more common among the parents of disabled children compared to the parents of children with a normal development. In addition, significant differences were found between the parents of disabled children and the parents of children with a normal development in terms of the "difficulty identifying feelings" $(\mathrm{F}=18.611, p<.05$, $\eta 2=.054)$ and "difficulty describing feelings" $(\mathrm{F}=19.249, p<.05$, $\eta 2=.056)$ sub-dimensions of TAS-20 and flourishing $(\mathrm{F}=7.779, p<.05$,
\end{abstract}


$\eta 2=.023$ ). However, no significant difference was determined between the two groups in terms of the "externally oriented thinking" sub-dimension. Moreover, it was found out that while the mothers having both disabled and healthy children have increased alexithymia and decreased flourishing, no statistically significant relationship was detected between them for the fathers having both disabled and healthy children. It can be said that due to the psychological problems experienced, the parents having disabled children may display alexithymic characteristics and have less flourishing.

Keywords: Alexithymia; Flourishing; Parents with disabled children; Expression of emotions.

\section{Extended Summary}

\section{Purpose}

Alexithymia refers to having difficulty in expressing emotions (Sifneos, 1991). It is reported that alexithymic individuals have poor imaginations (Taylor, Bagby and Parker, 1997) and have difficulty in communicating with others (Sifneos, 1991), in identifying and expressing their emotions, and in concrete thinking (Koçak, 2002). Also, individuals may display alexithymic attitudes when they have psychological problems (Cole, 1991; Son et. al., 2012; Wrana, Bruder, Thomas, Lane ve Köhle, 2005). Psychologic alexithymia is a situation that may emerge following traumatic and stressful life events and continues for a while (Freyberg, 1977). The people with this sort of alexithymia keep their positive emotions in the background and are heavily surrounded by negative emotions (Sifneos, 1991; Taylor, 1994). Having a disabled child is considered to be a traumatic event on its own (Ardiç, 2013; Küçük and Alemdar, 2017; Xiang et. al., 2017). Parents having disabled children may have intense anxiety and stress and as a result fall into depression. There is a strong relationship between alexithymia and anxiety, depression, and intense stress that the parents of disabled children often experience (Al-Eithan, Juban and Robert, 2012). The level of alexithymia, which can be identified with negative experiences, affects the individual's flourishing as well. Flourishing refers to the capability of individuals to turn to their own needs in the face of challenging events experienced, to realize themselves, and to try to make their lives meaningful (Diener et. al., 2010). In this regard, it can be said that parents having disabled children can alleviate the intensity of their possible psychological problems and negative emotions by turning to their own needs. At this point, it is very important for parents to identify and express their emotions. 
The purpose of the present study is to investigate the relationship between the alexithymia levels and the flourishing levels of parents having children with a normal development and of those having disabled children. To this end, an attempt was made to answer the below-mentioned questions:

1. How common is alexithymia among parents having children with a normal development and those having disabled children?

2. Is there a significant difference between the alexithymia levels and the flourishing levels of parents having children with a normal development and of those having disabled children?

3. Is there a relationship between the alexithymia levels and the flourishing levels of parents having both healthy and disabled children?

\section{Method}

Relational survey model was used in the study. The study group consists of 326 parents. Of the participants, 161 (97 mothers and 64 fathers) were parents of disabled children attending Anadolu University Research Institute for Individuals with Disabilities in the spring semester of 2017 and 165 (113 mothers and 52 fathers) were parents of children with a normal development attending nursery classes of schools affiliated with the Republic of Turkey Ministry of National Education. The research data were collected through Toronto Alexithymia Scale (TAS-20), Flourishing Scale (FS), and personal information form. The data were analyzed based on frequency and percentage values, one-way MANOVA, and Pearson's product-moment correlation coefficient statistics.

\section{Results}

The prevalence of alexithymia was found to be $24.2 \%$ among the parents with disabled children and $8.5 \%$ among the parents having children with a normal development. The prevalence of alexithymia was determined to be $20.8 \%$ among the mothers with disabled children, $52.8 \%$ among the fathers with disabled children, $7.5 \%$ among the mothers having children with a normal development, and $18.9 \%$ among the fathers having children with a normal development. According to the results of one-way MANOVA, there is a significant difference between the flourishing levels and the mean scores obtained from the sub-dimensions of TAS-20 of the parents having disabled children and of the parents having children with a normal development $(\lambda=.911$, $\mathrm{F}=7.859, p<.05$ ). Lastly, while a negative correlation was found between the 
flourishing levels and the alexithymia levels of the mothers having both disabled and healthy children, no statistically significant difference was detected between the flourishing levels and the mean scores obtained from the subdimensions of TAS-20 of the fathers having both disabled and healthy children.

\section{Discussion and Conclusion}

The research findings indicate that alexithymia is more common among the parents with disabled children compared to the parents having children with a normal development. This may be because encountering an unexpected situation like having a disabled child leads to some changes in their lives and causes certain psychological problems. The findings also show that alexithymia is more common among fathers compared to mothers in case of having both disabled and healthy children. However, expression of emotions should be considered along with cultural factors (Mesquita, 2001; Planalp, 1999). It should be noted that due to gender roles arising from cultural factors, men may tend to hide their emotions resulting from their psychological problems.

Based on the research findings, it can also be said that there are significant differences between the parents of disabled children and the parents of children with a normal development in terms of the "difficulty identifying feelings" and "difficulty describing feelings" sub-dimensions of TAS-20 and flourishing. The difference between the two groups in terms of alexithymic characteristics may be a result of the confrontation of the parents having disabled children with a traumatic life event. The difference between the groups in terms of flourishing may result from the fact that the parents with disabled children consider the needs of their children rather than their own needs as a life purpose.

Lastly, a negative correlation was detected between the alexithymic levels and the flourishing levels of the mothers having both disabled and healthy children. However, no significant correlation was identified between the alexithymic levels and the flourishing levels of the fathers having both disabled and healthy children. This may be revealing that the alexithymic characteristics of fathers are affected by cultural factors besides depression, anxiety, stress, and traumatic life events. It can be said that alexithymia is associated with depression and anxiety; psychological problems such as depression and anxiety can be experienced by mothers more (Al-Eithan, Juban and Robert, 2012) and thus alexithymic characteristics are observed in mothers more. 


\section{Giriş}

Ebeveynler hayatlarına yeni bir üyenin katılacağını öğrendikleri andan itibaren olumlu hayaller kurabilirler. Ancak çocuğun herhangi bir engeli olduğunu öğrendikten sonra ebeveynlerin olumlu hayallerinin yerini hayal k1rıklıkları alabilir. Çocukla ilgili beklenmedik durumlarla karşı karşıya kalmak her ebeveyn için zor olabilmekte ve olumlu duyguların yerini olumsuz duygulara bırakmasıyla psikolojik zorlanmalarla karşılaşabilmektedirler. Ebeveynler, yaşamlarını çocuklarının iyileşmesine adayabilir ve kendi ihtiyaçlarını ihmal edebilirler. Nitekim ebeveynler, olumsuz duyguları yoğun olarak yaşamalarına rağmen duygularını tanımlamakta ve ifade etmekte zorluk çekebilirler.

Duyguları ifade etmekte zorluk yaşama "Duygusal Sağırlık (Aleksitimi)" kavramiyla ifade edilmektedir (Sifneos, 1991). Aleksitimik bireylerin, hayal dünyalarının zayıf olduğu (Taylor, Bagby ve Parker, 1997), başkalarıyla iletişime geçmekte zorlandıkları (Sifneos, 1991), duyguları tanımakta, aktarmakta ve somut düşünmede güçlük yaşadıkları görülmektedir (Koçak, 2002). Duygusal sağırlık, psikosomatik hastalara ait bir kavram olarak doğmasına rağmen günümüzde ruhsal ve fiziksel hastalıklarda (Pedrosa, Weigl, Wessels, Irnich, Baumüller ve Winkelman, 2008) hatta genel dağılımda da görülebildiği savunulmaktadır (Levant, Hall, Williams ve Hasan, 2009; Salminen, Saarijärvi, Äärelä, Toikka ve Kauhanen, 1999; Tolmunen, Heliste, Lehto, Hintikka, Homkalampi ve Kauhanen, 2011). Bu nedenle herhangi bir klinik durumu (belli bir psikolojik rahatsızlığı) olmayan ancak yaşamda psikolojik zorlanmalarla karşılaşan bireyler de duygusal sağırlık özellikleri gösterebilmektedir (Cole, 1991; Son ve ark., 2012; Wrana ve ark., 2005).

Psikolojik duygusal sağırlık, travmatik ve stresli yaşam olaylarından sonra ortaya çıkabilen ve belirli bir süre devam eden durumdur (Freyberg, 1977). Bu duygusal sağırlığa sahip kişilerin, olumlu duygularını geri planda tutarak yoğun şekilde olumsuz duygularla çevrelendiği görülmektedir (Sifneos, 1991; Taylor, 1994). Yapılan çalışmalarda da duygusal sağırlığın, travmatik yaşam olaylarıyla ve olumsuz duygulara eşlik eden anksiyete ve depresyon gibi durumlarla ilişkisi olduğu bildirilmektedir (Honkalampi, Hintikka, Laukkanen, Lehtonen ve Viinamäki, 2001; Leweke, Leichsenring, Kruse ve Hermes, 2012; Lumley, 2000). Bir başka ifadeyle, psikolojik zorlanma yaşayan bireylerin duygularını tanımakta ve ifade etmekte zorlanması, hem beden hem de ruh sağlıklarını olumsuz etkilemektedir (Kenndy-Moore ve Watson, 
2001; King ve Emmons, 1990; Pennebaker, 1995).

Engelli çocuğa sahip olmak da başlı başına travmatik bir olay olarak kabul edilmektedir (Ardıç, 2013; Küçük ve Alemdar, 2017; Xiang ve ark., 2017). Travmatik anıların ansızın hatırlanabilmesi veya bu anılardan kaçınmaya çalışılması psikolojik problemlerin ortaya çıkmasında etkendir (APA, 2000). Bununla birlikte, engelli çocuğa sahip ebeveynlerin travmatik anılarının her an göz önünde olduğu düşünüldügünde psikolojik problemleri süreklilik gösterebilir. Bu ebeveynler, yoğun şekilde anksiyete ve stres içinde olabilmekte (Gerstein, Crnic, Blacher ve Baker, 2009; Woolf, Muscara, Anderson ve McCarty, 2016) ve depresyona girebilmektedir (Montes ve Halterman, 2007; Kaur, 2010). Olumsuz duygularla çevrelenen ebeveynler (Corcoran, Berry ve Hill, 2015), ilişkilerinde sorunlar yaşayabilir ve sosyal olarak yalnızlık hissedebilirler (Gupta ve Singhal, 2004). Engelli çocuğa sahip ebeveynler, güçlü bir şekilde sosyal çevresi tarafindan reddedilme korkusu yaşamaktadır (Oelofsen ve Richardson, 2006). Tüm bu zorluklarla birlikte hiç kimsenin hissettiklerini anlamayacağına inanan ebeveynler, duygularını ifade etmekte ve tanımakta zorlanabilirler.

Bununla birlikte, engelli çocuk ebeveynlerinde sıklıkla rastlanan anksiyete, depresyon ve yoğun stres durumlarıyla duygusal sağırlık arasında güçlü bir ilişkinin olduğu görülmektedir (Al-Eithan, Juban ve Robert, 2012). Yap1lan sınırlı çalışmalarda, normal gelişim gösteren çocuğa sahip annelere göre engelli çocuğa sahip annelerin duygusal sağırlık düzeylerinin daha yüksek olduğu, anksiyete ve depresyon gibi psikolojik semptomların duygusal sağırlıkla ilişkili olduğu (Al-Eithan, Juban ve Robert, 2012), ebeveynlerin duygusal sağırlık düzeyleri yükseldikçe yaşam doyumu düzeylerinin azaldığı sonucuna ulaşılmıştır (Genç, 2015). Buna karşın, otizmli ve zihin yetersizliği olan çocuğa sahip ebeveynlerin (Fırat, 2000) ve otistik ve normal gelişim gösteren çocuğa sahip ebeveynlerin (Öksüz, 2008) duygusal sağırlık düzeyleri arasında anlamlı bir fark bulunmadığ da bildirilmektedir. Bu ebeveynler normal gelişim gösteren çocuğa sahip ebeveynlerle karşılaştırıldığında değişen yaşam koşullarının baskısıyla daha fazla olumsuz duygu durumu gösterebilmektedir (Piven ve ark., 1991; Oelofsen ve Richardson, 2006). Olumsuz yaşantılarla birlikte değerlendirilebilen duygusal sağırlı̆̆ın düzeyi, bireyin psikolojik iyi oluşunu da etkilemektedir (Holder, Love ve Timoney, 2015).

Psikolojik iyi oluş (flourishing), bireylerin yaşamlarında karşılaştıkları zorlayıcı olaylar karşısında kendi ihtiyaçlarına yönelebilmesi, kendini 
gerçekleştirebilmesi ve hayatını anlamlı hâle getirebilmesi için çaba göstermesi olarak değerlendirilmektedir (Diener ve ark., 2010). Bununla beraber psikolojik iyi oluş, kendine ve başkalarına saygı duymayı, sosyal ilişkilerinde destekleyici (Dunn, Aknin ve Norton, 2008), amacı olan anlamlı bir hayata sahip olmayı içermekte ve kendini kabul etmekle ilişkilidir (Diener ve ark., 2010; Ryff ve Singer, 2008). Bireyin sadece olumlu değil olumsuz duygularını da (Huppert, 2009) tanıması ve ifade etmesi psikolojik iyi oluşunu arttırabilmektedir (Kuyumcu ve Güven, 2012; Lundh, Johnson, Sundqvist ve Olsson, 2002; Novick-Kline, Turk, Mennin, Hoyt ve Gallager, 2005; Thimm ve Lenelis, 1993). Bir başka ifadeyle, bireylerin sosyal ilişkilerinden doyum sağlayabilmesi ve kendi ihtiyaçlarına yönelebilmesi, duygularının farkında olmasıyla ilişkilidir (Keltner ve Haidt, 2001; Lopes, Brackett, Nezlek, Schütz, Sellin ve Salovey, 2004). Bununla birlikte, depresyon, anksiyete ve olumsuz yaşam olaylarının duygusal sağırlıkla güçlü bir ilişkisinin olabileceği düşünüldügünde (Gilbert, McEwan, Gibbons, Chotai, Duarte ve Matos, 2012; Lundh ve Sarnecki, 2001) duygusal sağırlık özelliği gösteren bireylerin psikolojik iyi oluşları da olumsuz etkilenebilir. Engelli çocuğa sahip ebeveynler, karşılaşabildikleri psikolojik zorlanmalar ve olumsuz duygulara rağmen kendi ihtiyaçlarına yönelmeleriyle bu olumsuzlukların yoğunluğunu azaltabileceklerdir (Duckworth, Steen ve Seligman, 2005; Pavot ve Diener, 2008).

Bireylere sunulan psikolojik desteğin yararlı olmasında duyguların tanınması ve ifade edilmesini önemlidir. Duygusal sağırlık özellikleri gösteren bireylere sunulan bazı psikolojik yardım çalışmalarının bireylerin duygularını tanımasına ve dolayısıyla psikolojik sağl1klarına olumlu katkı sağlayabileceği belirtilmektedir (Freyberg, 1977; Fukunishi, Kikuchi ve Takubo, 1997; Honkalampi ve ark., 2001). Bununla beraber engelli çocuğa sahip ebeveynlerin içsel süreçlerini dikkate almaksızın onlara yardımcı olmaya çalışmak başarısızlıkla sonuçlanacaktır (Zaidman-Zait ve Curle, 2015). Alanyazın incelendiğinde normal ve engelli çocuğa sahip ebeveynlerde duygusal sağırlık yaygınlığının ve duygusal sağırlık ile psikolojik iyi oluşun birlikte ele alındığı çalışmaya rastlanmamaktadır. Ayrıca psikolojik iyi oluş ile duygusal sağırlığın birbirinin zıddı olabilecek niteliklere sahip olduğu görülmektedir. Bireylerin psikolojik sağlığı için çaba göstermelerine yardımcı olacak profesyonellerin öncelikle bireyde duygusal sağırlık özelliklerinin varlığını irdelemesinin yararlı olabileceği ifade edilebilir. Bu nedenlerden dolayı engelli çocuğa sahip ebeveynlerin duygusal sağırlık düzeylerinin ve psikolojik iyi oluşlarının ortaya konulmasının önemli olduğu düşünülmektedir. Bu çalışmanın amacı, normal 
gelişim gösteren ve engelli çocuğa sahip ebeveynlerin duygusal sağırlık düzeyleri ve psikolojik iyi oluşları arasındaki ilişkinin incelenmesidir. Bu amaç doğrultusunda şu sorulara yanıt aranmıştır:

1. Normal gelişim gösteren ve engelli çocuğa sahip ebeveynlerde duygusal sağırlık düzeyi nedir?

2. Engelli çocuğa sahip ebeveynler ile normal gelişim gösteren çocuğa sahip ebeveynlerin duygusal sağıllık özellikleri ve psikolojik iyi oluşları arasında anlamlı bir fark bulunmakta mıdır?

3. Hem engelli hem de normal gelişim gösteren çocuğa sahip anneler ve babaların duygusal sağırlık özellikleriyle psikolojik iyi oluşları arasında bir ilişki var mıdır?

\section{Yöntem}

\section{Araştırmanın Deseni}

$\mathrm{Bu}$ araştırma ilişkisel tarama modelindedir. $\mathrm{Bu}$ doğrultuda elde edilen veriler nicel teknikler kullanılarak analiz edilmiştir.

\section{Çalışma Grubu}

Araştırmanın çalışma grubunu, 2017 bahar döneminde Anadolu Üniversitesi Engelliler Araştırma Enstitüsü’nde eğitimlerine devam eden engelli çocukların 161 ebeveyni (97 anne ve 64 baba) ve Millî Eğitim Bakanlığı'na bağlı okullarda anasınıfina devam eden normal gelişim gösteren çocukların 165 ebeveyni (113 anne ve 52 baba) olmak üzere 326 anne-baba oluşturmaktadır. Grupları olabildiğince eşitlemek amacıyla çalışma grubuna alınan tüm ebeveynlerin, algılanan sosyo-ekonomik düzeyinin orta düzeyde olması, boşanmamış, eşlerden birisinin vefat etmemiş ve çocuklarının 4-6 yaş aralığında olması sağlanmıştır. Ayrıca ebeveynlerin, şu an ve/veya geçmişte herhangi bir psikiyatrik tedavi ve/veya ilaç kullanmamış olmasının normal dağılımda olduğu varsayılmış dolayısıyla çalışmaya dâhil edilmiştir. Engelli çocuğa sahip ebeveynlerin \%45'i otizm spektrum bozukluğu, \%29'u down sendromu, \%11'i özel öğrenme güçlüğü, \%8'i serebral palsi ve \%7'si dil ve konuşma bozukluğu tanısı almış çocuğa sahiptir.

\section{Veri Toplama Araçları}

$\mathrm{Bu}$ çalışmada veri toplamak amaciyla Toronto Aleksitimi Ölçeği (The Toronto Alexithymia Scale-20), Psikolojik İyi Oluş Ölçeği (Flourishing Scale) ve Kişisel Bilgi Formu kullanılmıştır. 
Toronto Aleksitimi Ölçeği (TAÖ-20): Bagby, Parker ve Taylor (1994) tarafından geliştirilen 20 maddeden oluşan ölçeğin Türkçe uyarlama çalışması Güleç ve arkadaşları (2009) tarafından gerçekleştirilmiştir. Ölçek "Hiçbir zaman" ve "Her zaman" arasında puanlanan 5'li likert tipindedir. Ölçek, "Duyguları tanımada zorluk", "Duyguları ifade etmekte zorluk" ve "Dışsal odaklı düşünce" olmak üzere üç alt boyuta sahiptir. Ölçekten alınan puanlar yükseldikçe bireylerdeki aleksitiminin (duygusal sağırlık) de yükseldiğini göstermektedir.

Ölçekten alınan puanlar 20 ile 100 arasında değişirken $\leq 61$ puan alanlar aleksitimik; 52 ile 60 puan arasındaki kişilerde sınırda aleksitimik; $\leq 51$ puan alanlarda aleksitimik olmayan kişiler olarak sınıflandırılmaktadır (Bagby, Parker ve Taylor, 1994; Taylor, 1994). Bu çalışmada duygusal sağırlık yaygınlığını ortaya koymak için 61 ve üstü puan alanlar dikkate alınmıştır. Ölçeğin alfa iç tutarlılık katsayısı toplam puanda .78 iken alt boyutlarında .57 ile .80 arasındadır (Güleç ve ark., 2009). Bu çalışmada iç tutarlık katsayısı toplam puanda .74 , alt ölçeklerde .47 ile .76 arasında bulunmuştur.

Psikolojik İyi Oluş Ölçeği (PIOÖ): Diener ve arkadaşları (2009) tarafından geliştirilen 8 maddeden oluşan ölçeğin Türkçe uyarlama çalışması Telef (2013) tarafından gerçekleştirilmiştir. Ölçeğin orjinali "Flourishing Scale" adını taşırken bu kelimenin karşılı̆̆ bulunamadığından "Psikolojik İyi Oluş Ölçeğì" şeklinde adlandırılmıştır. Ölçek "Kesinlikle katılıyorum” ve "Kesinlikle katılmıyorum" arasında puanlanabilen 7'li likert tipindedir. Ölçekten yüksek puan almak kişinin birçok psikolojik kaynak ve güce sahip olduğunu göstermektedir. Ayrıca ölçeğin orjinalinin iç tutarlılık katsayısı .87 iken Türkçe uyarlamasının .80 olarak bulunmuştur. Bu çalışmada iç tutarlık katsayıs1 .88 olarak bulunmuştur.

Kişisel Bilgi Formu: Araştırmacı tarafından hazırlanan bu formda, katılımc1ların anne-baba olma durumu, yaş, sosyo-ekonomik durumu, eğitim düzeyi, engelli çocuğa sahip olma durumu, çocuklarının engel tanısı, yaşı ile kendilerinin psikiyatrik tedavi alma veya psikolojik ilaç kullanma durumu gibi demografik bilgileri içermektedir.

\section{Veri Toplanması ve Analiz}

Veri toplama sürecinde ebeveynlere araştırmanın amacı, önemi hakkında yazılı veya sözlü bilgiler verilmiştir. Tüm katılımcıların gönüllülükleri esas alınmıştır. Veriler araştırmacı tarafından katılımcıların Engelliler Araştırma Enstitüsüne davet edilmesiyle toplanmıştır. Verilerin toplanma süresi 
ortalama otuz dakika sürmüştür. Verilerin analizinde SPSS 22 paket programı kullanılmıştır. İstatistiksel analizlerde öncelikle normallik dağılımına çarpıklık ve basıklık değerleriyle bakılmıştır. Çarpıklık ve basıklık değerleri -1.5 ve +1.5 arasındaysa verilerin normal dağılım gösterdiği kabul edilmiştir (Tabachnick ve Fidell, 2013). Bu çalışmada her bir alt grup için çarpıklık ve basıklık değerleri -1.211 ile 1.065 arasında değişmektedir. Varyansların homojenliğine Levene testiyle bakılmış ve grupların homojen olduğu görülmüştür. Duyguları tanımada güçlük $\mathrm{F}=0.003$, duyguları ifade etmede zorluk $\mathrm{F}=3.352$, dışsal odaklı düşünce $\mathrm{F}=2.116$, psikolojik iyi oluş $\mathrm{F}=0.958, p>.05$. Ayrıca, Box's $\mathrm{M}$ değerleri incelenerek varyans-kovaryans matrislerinin eşitliği varsayımının karşılandığı görülmüştür $(\mathrm{F}=1.184, p>.05)$. Bu çalışmada, frekans ve yüzde değerlerine, tek yönlü MANOVA ve pearson momentler çarpımı korelasyon katsayısı analizlerine yer verilmiştir.

\section{Bulgular}

Araştırmada öncelikle normal gelişim gösteren ve engelli çocuğa sahip ebeveynler arasında aleksitimi düzeyine bakılmıştır. TAÖ-20 toplam puanından 61 ve üstü alanlar aleksitimik olarak değerlendirilmiştir.

Tablo 1. Engelli ve Normal Gelişim Gösteren Çocuğa Sahip Ebeveynlerde Duygusal Sağırlık Düzeyi

\begin{tabular}{|c|c|c|c|c|c|c|c|}
\hline & & $\mathbf{N}$ & $\%$ & & & $\mathbf{N}$ & $\%$ \\
\hline \multirow{4}{*}{ EÇSE } & \multirow{2}{*}{$\leq 61$} & \multirow{2}{*}{39} & \multirow{2}{*}{24.2} & \multirow{2}{*}{ Anne } & $\leq 61$ & 11 & 20.8 \\
\hline & & & & & Toplam & 97 & 100 \\
\hline & \multirow{2}{*}{ Toplam } & \multirow{2}{*}{161} & \multirow{2}{*}{100} & \multirow{2}{*}{ Baba } & $\leq 61$ & 28 & 52.8 \\
\hline & & & & & Toplam & 64 & 100 \\
\hline \multirow{4}{*}{ NGÇSE } & \multirow{2}{*}{$\leq 61$} & \multirow{2}{*}{14} & \multirow{2}{*}{8.5} & \multirow{2}{*}{ Anne } & $\leq 61$ & 4 & 7.5 \\
\hline & & & & & Toplam & 113 & 100 \\
\hline & \multirow{2}{*}{ Toplam } & \multirow{2}{*}{165} & \multirow{2}{*}{100} & \multirow{2}{*}{ Baba } & $\leq 61$ & 10 & 18.9 \\
\hline & & & & & Toplam & 52 & 100 \\
\hline
\end{tabular}

Not: EÇS: Engelli çocuğa sahip ebeveynler; NGÇS: Normal gelişim gösteren çocuğa sahip ebeveynler

Tablo 1'e bakıldığında duygusal sağırlık düzeyi, engelli çocuğa sahip ebeveynlerde \%24.2 ( $\mathrm{n}=39)$; normal gelişim gösteren çocuğa sahip ebeveynlerde \%8.5 ( $\mathrm{n}=14)$ olarak bulunmuştur. Ayrıca duygusal sağırlık düzeyi engelli çocuğa sahip anneler arasında \%20.8 $(\mathrm{n}=11)$, babalarda \%52.8 $(\mathrm{n}=28)$; normal gelişim gösteren anneler arasında $\% 7.5(\mathrm{n}=4)$, babalarda ise $\% 18.9$ $(\mathrm{n}=10)^{\prime}$ dur. 
Tablo 2. Ebeveynlerin Engelli veya Normal Gelişim Gösteren Çocuğa Sahip Olma Durumuna Göre PİOÖ ve TAÖ-20 Alt Boyutlarına İlişkin Tek Yönlü MANOVA Sonuçları

\begin{tabular}{llccccc}
\hline Bağımlı Değişkenler & Ebeveynler & $\mathbf{N}$ & $\overline{\boldsymbol{X}}$ & $\mathbf{s S}$ & $\mathbf{F}$ & $\boldsymbol{p}$ \\
\hline \multirow{2}{*}{ DTZ } & EÇS & 161 & 2.4747 & .71457 & 18.611 & .002 \\
& NGÇS & 165 & 2.1429 & .67413 & & \\
\hline \multirow{2}{*}{ Di̇z } & EÇS & 161 & 2.5950 & .73890 & 19.249 & .001 \\
& NGÇS & 165 & 2.2558 & .65578 & & \\
\multirow{2}{*}{ DOD } & EÇS & 161 & 2.7306 & .74642 & 1.506 & .221 \\
\multirow{2}{*}{ PíO } & NGÇS & 165 & 2.6348 & .66072 & & \\
& EÇS & 161 & 5.0598 & 1.0663 & 7.779 & .006 \\
& NGÇS & 165 & 5.4129 & 1.2128 & & \\
\hline
\end{tabular}

Not: $(\lambda=.911 ; \mathrm{F}=7.859 ; p<.05 ; \eta 2=.089)$ DTZ: Duyguları tanımada zorluk; DİZ: Duyguları ifade etmekte zorluk; DOD: Dışsal odaklı düşünce; Pİ: Psikolojik iyi oluş.

Tablo 2'de görüldüğü gibi tek yönlü MANOVA sonuçları incelendiğinde, engelli ve normal gelişim gösteren çocuğa sahip ebeveynlerin psikolojik iyi oluş düzeyleri ile Toronto aleksitimi ölçeğinin alt boyutlarından aldıkları puan ortalamaları arasında anlamlı bir farklılık olduğu bulunmuştur $(\lambda=.911, \mathrm{~F}=7.859, p<.05)$. Ebeveynlerin, psikolojik iyi oluş düzeyleri ve Toronto aleksitimi ölçeğinin alt boyutlarından aldıkları puan ortalamaları ve standart sapma değerleri ile engelli veya normal gelişim gösteren çocuğa sahip olma durumuna göre yapılan tek yönlü ANOVA sonuçları da "duyguları tan1mada zorluk" $(\mathrm{F}=18.611, p<.05, \eta 2=.054)$, "duyguları ifade etmede zorluk" $(\mathrm{F}=19.249, p<.05, \eta 2=.056)$ ve "psikolojik iyi oluş" düzeyleri $(\mathrm{F}=7.779$, $p<.05, \eta 2=.023$ ) arasında engelli veya normal gelişim gösteren çocuğa sahip olma durumuna göre anlamlı farklılıklar gösterdiği ortaya koymuştur.

Engelli veya normal gelişim gösteren çocuğa sahip olma durumuna göre beliren bu farkın hangi gruptan kaynaklandığını belirlemek için ortalama ve standart sapma değerlerine bakıldığında, "duyguları tanımada zorluk" ve "duyguları ifade etmede zorluk" alt boyutlarıyla psikolojik iyi oluş düzeyleri ortalamaları arasında normal gelişim gösteren çocuğa sahip ebeveynlerin lehine istatistiksel olarak anlamlı bir farklılık bulunmuştur. Ancak, engelli ve normal gelişim gösteren çocuğa sahip ebeveynlerin "dışsal odaklı düşünce" alt boyutundan aldıkları puan ortalamaları arasında istatistiksel olarak anlamlı bir farkl11ık bulunmamıştır $(\mathrm{F}=1.506, p>.05, \eta 2=.005)$. Bununla birlikte ebeveynlerin, engelli veya normal gelişim gösteren çocuğa sahip olma durumu bağımsız değişkeninin etki büyüklüğünü belirlemek için eta kare ( $\eta 2)$ değerine bak1lmıştır. Elde edilen eta kare değeri $\eta 2 \leq 0.01$ için küçük, $\eta 2=0.06$ için 
orta ve $\eta 2=0.14$ için büyük etki büyüklüğü olarak yorumlanmaktadır (Stevens, 1992). Bu açıdan, ebeveynlerin, engelli veya normal gelişim gösteren çocuğa sahip olma durumu açısından elde edilen eta kare değerine $(\eta 2=.089)$ bakıld1ğında orta büyüklükte bir etkiye sahip olduğu görülmektedir.

Tablo 3. Engelli Çocuğa Sahip Annelerin TAÖ-20’nin Alt Boyutlarıyla PİOÖ’ne İlişkin Korelasyon Katsayıları

\begin{tabular}{lcccccc}
\hline \multirow{2}{*}{ Ölçekler ve Boyutları } & \multicolumn{2}{c}{ PİO } & \multicolumn{2}{c}{ DTZ } & \multicolumn{2}{c}{ DİZ } \\
\cline { 2 - 7 } & EA & NA & EA & NA & EA & NA \\
\hline DTZ & $-.40^{* *}$ & $-.21^{*}$ & - & - & & \\
DİZ & $-.42^{* *}$ & $-.36^{* *}$ & $.51^{* *}$ & $.39^{* *}$ & - & - \\
DOD & $-.39^{* *}$ & $-.26^{* *}$ & $.29^{* *}$ & $.35^{* *}$ & $.50^{* *}$ & $.40^{* *}$ \\
\hline
\end{tabular}

Not: $\left({ }^{*} p<.05, * * p<.01\right)$ EA: Engelli çocuğa sahip anneler; NA: Normal gelişim gösteren çocuğa sahip anneler.

Tablo 3'te görüldüğü gibi, engelli çocuğa sahip annelerin psikolojik iyi oluş düzeyleri ile TAÖ-20'nin duyguları tanımada zorluk $(\mathrm{r}=-.40, p<.01)$, duyguları ifade etmede zorluk $(\mathrm{r}=-.42, p<.01)$ ve dişsal odaklı düşünce $(\mathrm{r}=.39$, $p<.01)$ alt boyutları arasında negatif yönlü orta düzeyde korelasyon olduğu görülmüştür. Bununla birlikte, normal gelişim gösteren çocuğa sahip annelerin psikolojik iyi oluş düzeyleri ile TAÖ-20'nin duyguları tanımada zorluk $(\mathrm{r}=-.21, p<.05)$ ve dişsal odaklı düşünce $(\mathrm{r}=-.26, p<.01)$ alt boyutları arasında negatif yönlü düşük düzeyde korelasyon olduğu gözlenirken; duyguları ifade etmede zorluk $(\mathrm{r}=-.36, p<.01)$ alt boyutu arasında negatif yönlü orta düzeyde korelasyon olduğu bulunmuştur. Ancak hem engelli hem de normal gelişim gösteren çocuğa sahip babaların psikolojik iyi oluş düzeyleri ile TAÖ-20'nin alt boyutları arasında istatistiksel olarak anlamlı bir ilişki bulunmamıştır.

\section{Tartışma, Sonuç ve Öneriler}

Araştırmada öncelikle engelli ve normal gelişim gösteren çocuğa sahip ebeveynlerde duygusal sağırlık düzeyine bakılmış ve engelli çocuğa sahip ebeveynlerde duygusal sağırlık düzeyi \%24.2 iken normal gelişim gösteren çocuğa sahip ebeveynlerde ise \%8.5 olarak bulunmuştur. Bu sonuç, engelli çocuğa sahip ailelerde duygusal sağırlığın normal gelişim gösteren çocuğa sahip ailelere oranla daha yaygın olduğunu göstermektedir. Araştırmalar engelli çocuğa sahip ebeveynlerin normal gelişim gösteren çocuğa sahip ebeveynlere oranla daha yoğun anksiyete, depresyon, olumsuz duygu durumu ve psikolojik zorlanmalar yaşadıkları (Piven ve ark., 1991; Oelofsen ve Richardson, 2006) ve duygusal sağırlık düzeylerinin de daha yüksek olduğunu (Al-Eithan, Juban ve Robert, 2012) göstermektedir. Ailenin çocuğun engelli olmas1 gibi beklenmedik bir durumla karşılaşması sonucu yaşantılarında değişiklikler meydana 
gelmesine ve psikolojik problemlerle yüzleşmelerine neden olabilir. Bu nedenle engelli çocuğa sahip ebeveynlerde duygusal sağırlık özellikleri daha yaygın görülebilir.

$\mathrm{Bu}$ araştırmada duygusal sağırlığın, engelli çocuğa sahip ebeveynlerde daha yaygın görülmesinin yanında hem engelli hem de normal gelişim gösteren babaların annelere göre daha yüksek duygusal sağırlık özellikleri gösterdikleri sonucuna ulaşılmıştır. Benzer şekilde Aydın ve Saraç (2014), otistik çocuğa sahip babaların annelere göre daha fazla duygusal sağırlık özellikleri gösterdiği sonucuna ulaşmıştır. Nitekim literatürde kadınlara göre erkeklerde duygusal sağırlık düzeyinin daha fazla olduğunu belirten bazı araştırmalar (Levant ve ark., 2009; Matilla, Ahola, Honkonen, Salminen, Huhtala ve Joukamaa, 2007; Salmien ve ark., 1999) bu bulguyu desteklemektedir. Ancak bazı araştırmalar da duygusal sağırlık özellikleriyle cinsiyet arasında herhangi bir farklılığın olmadığını belirtmektedir (Batıgün ve Büyükşahin, 2008). Bu araştırmanın özellikle çalışma grubunda yer alan engelli çocuğa sahip babaların yarısından fazlasında duygusal sağırlığın yaygın olarak görülmesinde, babaların bireysel psikolojik zorlanmalarının yanında ülkemizin ataerkil yapısı ve erkeklere biçilen görev ve sorumluluklar nedeniyle kültürel faktörlerin de etkili olabileceği söylenebilir.

Duyguları tanıma ve ifade etmede zorluk yaşama olarak tanımlanan duygusal sağırlığın kültürden etkilenebileceği ifade edilmektedir (Kuyumcu ve Güven, 2012). Bu nedenle duyguları ifade etmek kültürel öğretilerle beraber değerlendirilmelidir (Mesquita, 2001; Planalp, 1999). Kültürün etkisiyle toplumsal cinsiyet rolleri devreye girmekte ve erkekler psikolojik problemleri dolayısıyla duygularını gizleme eğilimi göstermektedirler (Johnson, 2001). Levant (1992), küçük yaşlardan itibaren erkeklerin duygularını bastırmayı öğrenmesi gibi duygusal sağırlığın cinsiyet rolleriyle ilişkili olduğunu savunmaktadır. Kadınlar ise, psikolojik problemlerini daha rahat ifade edebilmekte ve duygularını başkalarıyla paylaşma konusunda herhangi bir çekince duymamaktadırlar (Ang, Lim, Tan ve Yau, 2004). Benzer şekilde Le, Berenbaum ve Raghaum (2002), Batı ve Asya kültürleri arasında duygusal sağırlık özelliklerinin farklılaştığını bulmuştur. Bu durum duyguların ifade edilmesinde kültürün önemli bir etken olduğunu ortaya koyabilir. Nitekim Türkiye'de, "erkekler ağlamaz" gibi duyguların ifade edilmesini engelleyen cinsiyet rollerinin öğretilmesi bu çalışmada erkeklerin daha yüksek duygusal sağırlık özellikleri göstermesini desteklediği düşünülmektedir. 
$\mathrm{Bu}$ araştırmada ikinci olarak, engelli ve normal gelişim gösteren çocuğa sahip ebeveynler arasında duygusal sağırlık özellikleri ve psikolojik iyi oluşlarının anlamlı düzeyde farklılaşıp farklılaşmadığı sorusuna yanıt aranmıştır. Bu bulgulara bakıldığında, engelli ve normal gelişim gösteren ebeveynler arasında TAÖ-20'nin duyguları tanımada zorluk ve duyguları ifade etmede zorluk alt boyutları ile psikolojik iyi oluşlarının anlamlı düzeyde farklılaştığı sonucuna ulaşılmıştır. Yapılan çalışmalarda, otizmli ve sağlıklı çocuğa sahip anneler arasında duygusal sağırlık özelliklerinin farklılık gösterdiği (Aygen, 2011), otizmli çocuğa sahip annelerin daha yüksek duygusal sağırlık özellikleri gösterdiği (Szatmari, Georgiades, Duku, Zwaigenbaum, Goldberg ve Bennett., 2008) görülmüş̧ür. Bunun yanında otizmli ve normal gelişim gösteren çocuğa sahip ebeveynler arasında (Öksüz, 2008), otizmli ve zihin engelli çocuğa sahip ebeveynler arasında anlamlı bir farklılık olmadığını (Fırat, 2000) gösteren araştırmalar da vardır. İki grup arasında duygusal sağırlık özelliklerinin farklılık göstermesi, engelli çocuğa sahip ebeveynlerin travmatik yaşam olayıyla karşılaşmasının bir sonucu olduğu söylenebilir. Ebeveynler, sağlıklı bir çocuk beklerken çocuklarının herhangi bir engeli olduğunu öğrenmesi onlar için travmatik bir olaydır (Ardıç, 2013; Küçük ve Alemdar, 2017; Xiang ve ark., 2017). Ayrıca duygusal sağırlığın, travmatik bir yaşam olayı sonrasında ortaya çıkan psikolojik zorlanmalardan kaçınmak için bir başa çıkma yolu olarak oluşabileceği de savunulmaktadır (Lumley, 2000). Travmatik yaşam olayları sonrasındaki psikolojik zorlanmalarla duygusal sağırlık özellikleri arasında güçlü bir ilişkinin olduğunu ortaya koyan araştırmalar da (Gerstein ve ark., 2009; Kaur, 2010; Woolf ve ark., 2016) bu bulguyu desteklemektedir. Ayrıca bu çalışmada engelli ve normal gelişim gösteren ebeveynler arasında TAÖ-20'nin dışsal odaklı düşünce alt boyutu arasında istatistiksel olarak anlamlı bir farklılık bulunmamıştır. Bu nedenle duygusal sağırlığın, kişilik özelliğinden ziyade zorlayıcı yaşam olayları karşısında duygusal değişimlerle ortaya çıkabilen psikolojik bir durum (Freyberg, 1977) olabileceği görüşünü de desteklemektedir.

Engelli ve normal gelişim gösteren ebeveynlerin psikolojik iyi oluşları arasında anlamlı düzeyde farklılık bulunması araştırmanın bir başka bulgusudur. Psikolojik iyi oluş, bireylerin yaşamda karşılaş̧tıkları zorlayıcı olaylara rağmen kendi ihtiyaçlarına yönelebilmesi ve kendini gerçekleştirme yolunda çaba göstermesi anlamına gelmektedir (Diener ve ark., 2010). Ancak engelli çocuğa sahip ebeveynler, yaşam amacı olarak kendilerini değil çocuklarının ihtiyaçlarını göz önünde bulundurmaktadır (Dunst, 2002; Zaidman-Zait ve 
Curle, 2015). Ayrıca, psikolojik iyi oluşun bireylerin sosyal ilişkilerinden aldıkları doyumla da ilişkili olabileceği düşünülebilir. Engelli çocuğa sahip ebeveynler ise, yaşadıkları psikolojik zorlanmalar nedeniyle kendilerini yalnız hissedebilmekte ve yakın çevresine karşı duygusal izolasyon içine girebilmektedir (Oelofsen ve Richardson, 2006). Bu bilgiler, kendi ihtiyaçlarını göz ardı eden engelli çocuğa sahip ebeveynlerle normal gelişim gösteren çocuğa sahip ebeveynlerin psikolojik iyi oluşları arasında bir farklılık olduğu bulgusunu desteklemektedir.

Bu çalışmada son olarak, engelli ve normal gelişim gösteren anneler ve babaların duygusal sağırlık özellikleri ile psikolojik iyi oluşları arasındaki ilişski incelenmiştir. Bu bulgulara bakıldığında, hem engelli hem de normal gelişim gösteren annelerin duygusal sağırlık özellikleriyle psikolojik iyi oluşları arasında negatif yönde bir korelasyon olduğu bulunmuştur. Ancak, hem engelli hem de normal gelişim gösteren çocuğa sahip babaların duygusal sağırlık özellikleriyle psikolojik iyi oluşları arasında istatistiksel olarak anlamlı bir korelasyon olmadığı sonucuna ulaşılmıştır. Duygusal sağırlığın psikolojik iyi oluşla ilişkili olduğu söylenebilir. Nitekim Paez, Seguel ve Martinez-Sanchez (2013), duygusal sağırlık özellikleri yükseldikçe psikolojik iyi oluş düzeylerinin azalma eğilimi gösterdiğini bulmuşlardır. Alanyazındaki bazı çalışmalarda bu bulguyu desteklemektedir (Mikolajczak, Luminet ve Menil, 2005; Velasco, Fernandez, Paez ve Campos, 2006). Fakat bu çalışmada, psikolojik iyi oluş ile duygusal sağırlık arasındaki ilişki sadece anneler arasında gözlenmektedir. Bu durumda babalarda görülen duygusal sağırlık özelliklerinin sadece depresyon, anksiyete, stres ve travmatik yaşam olaylarından değil kültürel öğretilerden de etkilendiğini ortaya koyabilir. Bununla beraber Al-Eithan, Juban ve Robert (2012), duygusal sağırlığın depresyon ve anksiyeteyle ilişkili olduğunu ve annelerde, depresyon ve anksiyete gibi psikolojik zorlanmaların daha fazla görülebileceğini bundan dolayı da duygusal sağırlık özelliklerinin daha yüksek olabileceğini söylemektedir. Anneler babalara göre, sahip olduğu enerjilerini daha çok çocuklarının ihtiyaçları için harcayabilirler. Ayrıca engelli çocuğa sahip olan annelerin babalara göre daha fazla psikolojik zorlanma yaşadıkları bilinmektedir (Rodriguez ve Murphy, 1997). Bu nedenle, duygusal sağırlığın depresyon, anksiyete ve stres gibi psikolojik zorlanmalarla ve travmatik yaşam olaylarıyla arasındaki ilişki (Honkalampi ve ark., 2001; Leweke ve ark., 2012; Lumley, 2000) göz önüne alındığında annelerin, duygusal sağırlık özellikleriyle psikolojik iyi oluşları arasında korelasyonel bir ilişkinin bulunması bulgusunu destekleyebilmektedir. 
Bireylerin sahip olduğu duygusal sağırlık özelliklerini ortaya koyan ölçümlere yönelik yapılan eleştiriler, bu çalışmanın sınırlılığı olarak düşünülmektedir. Duygusal sağırlık ölçümlerinde, bireylerde eksik olarak görülen duygular hakkında kendilerini değerlendirmesini istemek eleştiri konusu olmaktadır (Waller ve Scheidt, 2004). Ancak, duygusal sağırlık ölçeklerinde alt boyutların psikolojik zorlanmaları iyi bir şekilde yansıttığı da belirtilmektedir (Leising, Grande ve Faber, 2009). Bu nedenle ölçümlerin, nicel araştırmalar yanında nitel araştırmalarla da desteklenmesi, psikolojik duygusal sağırlığı daha iyi ortaya koyabileceği söylenebilir. Bu sayede bireylerin duygusal sağrlık özellikleri hakkında daha derinlemesine bilgiler edinilmesi ve bu bilgiler 1şığında bireylerin psikolojik iyi oluşlarını etkileyen (olumlu/olumsuz) faktörlerin kendi bakış açılarıyla ortaya konması sağlanabilir.

Sonuç olarak, engelli çocuğa sahip ebeveynlerin duygularını tanıma ve ifade etmede zorlandıkları görülmektedir. Bir başka ifadeyle, bu ebeveynlerin yaşadığı psikolojik zorlanmalar nedeniyle duygusal sağırlık özellikleri göstermeleri muhtemeldir. Psikolojik iyi oluş düzeylerinin yükselmesinde duyguların farkında olmanın önemli olduğu düşünüldüğünde, bu ebeveynlerin duygularını tanıma ve ifade etmesini geliştiren çalışmalar yapılmasının gerekli olduğu düşünülebilir. Bu açıdan, engelli çocuğa sahip ebeveynlerle çalışacak ruh sağlığı uzmanlarının bu ebeveynlerin duygularını paylaşma konusunda zorluk yaşadıklarının farkında olmaları ve bu durumu geliştiren grup rehberliği ya da grupla psikolojik danışma türü çalışmalara yönelmeleri önerilebilir, durumla başa çıkmalarını kolaylaştıracak sosyal etkinlikler düzenlenebilir. Ayrıca bundan sonraki çalışmalarda, engelli çocuğa sahip ebeveynlerin duygusal sağırlık özellikleri ve psikolojik iyi oluşlarıyla depresyon, anksiyete ve stres gibi psikolojik zorlanmalarla; kültürel öğretiler, yaş ve çocuk sayısı gibi demografik değişkenlerle ilişkisini daha net bir şekilde ortaya koyan çalışmaların yapılması; nitel çalışmalarla konunun derinlemesine incelenmesi önerilebilir.

\section{Kaynakça}

Al-Eithan, M. H., Juban, H. A. ve Robert, A. A. (2012). Alexithymia among Arab mothers of disabled children and its correlation with mood disorders. Saudi Medical Journal, 33(9), 995-1000.

Ang, R. P., Lim, K. M., Tan, A. ve Yau, T. Y. (2004). Effects of gender and sex role orientation on help seeking attitudes. Current Psychology, Developmental, Learning, Social, 23(3), 203-214. 
Doi:10.1007/s12144-004-1020-3

APA. (2000). Amerikan Psikiyatri Birliği ruhsal bozuklukların tanısal ve sayımsal el kitabı, (4.baskı) Yeniden gözden geçirilmiş tam metin (DSM$I V$-TR). (E. Köroğlu, Çev.). Ankara: Hekimler Yayın Birliği. (Orijinal çalışma basım tarihi 1994.)

Ardıç, A. (2013). Otistik spektrum bozukluğu tanısı almış çocukların ailelerine yönelik bir psiko-eğitsel grup programının ebeveynlerin bazı psikolojik değişkenleri üzerindeki etkisi. Yayınlanmamış doktora tezi, Anadolu Üniversitesi Eğitim Bilimleri Enstitüsü.

Aydın, A. ve Saraç, T. (2014). Otistik çocuk ebeveynlerinin geniş otizm fenotipi ve aleksitimi özellikleri arasındaki ilişki. Dumlupınar Üniversitesi Sosyal Bilimler Dergisi, 41, 297-308.

Aygen, S. (2011). Otizm tanısı almış çocuk ve ergenlerin annelerinde aleksitimi düzeyinin yordanması. Yayınlanmamış yüksek lisans tezi. Maltepe Üniversitesi Sosyal Bilimler Enstitüsü.

Bagby, R. M., Parker, J. D. A. ve Taylor, G. J. (1994). The twenty-item Toronto alexithymia scale I. Item selection and cross-validation of the factor structure. Journal of Psychosomatic Research, 38(1), 23-32.

Doi: 10.1016/0022-3999(94)90005-1

Batıgün, A. D. ve Büyükşahin, A. (2008). Aleksitimi: Psikolojik belirtiler ve bağlanma stilleri. Klinik Psikiyatri, 11, 105-114.

Cole, C. G. (1991). Alexithymia, stroop interference, and verbal abilities: Sex differences. Yayınlanmamış doktora tezi, Simon Fraser University, Canada.

Corcoran, J., Berry, A. ve Hill, S. (2015). The lived experience of US parents of children with autism spectrum disorders: a systematic review and meta-synthesis. Journal of Intellectual Disabilities, 19(4), 356-366.

Doi:10.1177/1744629515577876

Diener, E., Wirtz, D., Biswas-Diener, R., Tov, W., Kim-Prieto, C., Choi, D. ve Oishi, S. (2009). New measures of wellbeing. Social Indicators Research Series, 39, 247-266.

Doi:10.1007/978-90-481-2354-412

Diener, E., Wirtz, D., Tov, W., Kim-Prieto, C., Choi, D., Oishi, S. ve Biswas- 
Diener, R. (2010). New well-being measures: Short scales to assess flourishing and positive and negative feelings. Social Indicators Research, 97, 143-156.

Doi: 10.1007/s11205-009-9493-y

Duckworth, A. L., Steen, T. A. ve Seligman, M. E. (2005). Positive psychology in clinical practice. Annual Review of Clinical Psychology, 1, 629651.

Doi: 10.1146/annurev.clinpsy.1.102803.144154

Dunn, E., Aknin, L. B. ve Norton, M. I. (2008). Spending money on others promotes happiness. Science, 319, 1687-1688.

Doi: $10.1126 /$ science. 1150952

Dunst, C. J. (2002). Family-centered practices: Birth through high school. The Journal of Special Education, 36, 141-149.

Doi: $10.1177 / 00224669020360030401$

Fırat, S. (2000). Otistik ve zihinsel özürlü çocukların annelerinde kaygl, depresyon, aleksitimi ve genel psikolojik değerlendirme. Yayınlanmamış yüksek lisans tezi, Çukurova Üniversitesi Eğitim Bilimleri Enstitüsü.

Freyberger, H. (1977). Supportive psychotherapeutic tecniques in primary and secondery alexithymia. Psychotherapy and Psychosomatics, 28, 337345.

Doi: $10.1159 / 000287080$

Fukunishi, I., Kikuchi, M. ve Takubo, M. (1997). Changes in scores on alexithymia over a period of psychiatric treatment. Psychological Report, 80(2), 483-489.

Doi: $0.2466 /$ pr0.1997.80.2.483

Genç, H. (2015). Zihinsel engelli çocuklara sahip anne ve babaların yaşam doyumlarının ve aleksitimi düzeylerinin incelenmesi. Yayınlanmamış yüksek lisans tezi, Gaziosmanpaşa Üniversitesi Eğitim Bilimleri Enstitüsü.

Gerstein, E. D., Crnic, K. A., Blacher, J. ve Baker, B. L. (2009). Resilience and the course of daily parenting stress in families of young children with intellectual disabilities. Journal of Intellectual Disability Research, 53, 981-997.

Doi: $10.1111 / \mathrm{j} .1365-2788.2009 .01220 . x$ 
Gilbert, P., McEwan, K., Gibbons, L., Chotai, S., Duarte, J. ve Matos, M. (2012). Fears of compassion and happines in relation to alexithymia, mindfulness, and self-criticism. Psychology and Psychotherapy: Theory, Research and Practice, 85, 374-390.

Doi: 10.1111/j.2044-8341.2011.02046.x

Gupta, A. ve Singhal, N. (2004). Positive perceptions in parents of children with disabilities. Asia Pacific Disability Rehabilitation Journal, 15(1), 22-35.

Güleç, H., Köse, S., Güleç, M. Y., Çitak, S., Evren, C., Borckardt, J. ve Sayar, K. (2009). Reliability and factorial validity of the Turkish version of the 20-item toronto alexithymia scale. Klinik Psikofarmakoloji Bülteni, 19, 214-220.

Holder, M. D., Love, A. B. ve Timoney, L. R. (2015). The poor subjective well-being associated with alexithymia is mediated by romantic relationships. Journal of Happiness study, 16(1), 117-133.

Doi: 10.1007/s10902-014-9500-0

Honkalampi, K., Hintikka, J., Laukkanen, E., Lehtonen, J. ve Viinamäki, H. (2001). Alexithymia and depression: A prospective study of patients with major depressive disorder. Journal of Psychosomatics, 42(3), 229234.

Doi: 10.1176/appi.psy.42.3.229

Huppert, F. A. (2009). Psychological well-being: Evidence regarding its causes and consequences. Applied Psychology: Health and Well-Being, 1, 907-925.

Doi: $10.1111 / \mathrm{j} .1758-0854.2009 .01008 . x$

Johnson, M. E. (2001). Influences of gender and sex role orientation on helpseeking attitudes. The Journal of Psychology, 122, 237-241.

Doi:10.1080/00223980.1988.9915510

Kaur, Y. (2010). Family support model for the management of children with special educational needs children. Study Home Community Science, 4(3), 179-184.

Keltner, D. ve Haidt, J. (2001). Social functions of emotions. T. J. Mayne ve G. A. Bonanno, (Ed.), Emotions: Current issues and future directions içinde (192-213). New York: Guilford. 
Kenndy-Moore, E. ve Watson, J. C. (2001). How and when does emotional expression help? Review of General Psychology, 5(3), 187-212. Doi: 10.1037/1089-2680.5.3.187

King, L. A. ve Emmons, R. A. (1990). Conflict over emotional expression: Psychological and physical correlates. Journal of Personality and Social Psychology, 58(5), 864-877.

Doi: 10.1037/0022-3514.58.5.864

Koçak, R. (2002). Aleksitimi: kuramsal çerçeve tedavi yaklaşımları ve ilgili araştırmalar. Ankara Üniversitesi Eğitim Bilimleri Dergisi, 35(1-2), 183-212.

Kuyumcu, B. ve Güven, M. (2012). Türk ve İngiliz üniversite öğrencilerinin duygularını fark etmeleri ve ifade etmeleri ile psikolojik iyi oluşları arasındaki ilişki. Gazi Eğitim Fakültesi Dergisi, 32(3), 589-607.

Küçük, E. E. ve Alemdar, D. K. (2017). Life satisfaction and psychological status of mothers with disabled children: a descriptive study. Community Mental Health Journal, 54(11), 102-106.

Doi: 10.1007/s10597-017-0135-6

Le, H. N., Berenbaum, H. ve Raghavan, C. (2002). Culture and alexithymia: Mean levels, correlates and the role of parental socialization of emotions. Emotion, 2(4), 341-360.

Doi: $10.1037 / 1528-3542.2 .4 .341$

Leising, D., Grande, T. ve Faber, R. (2009). The Toronto Alexithymia Scale (TAS-20): a measure of general psychological distress. Journal of Research in Personality, 43(4), 707-710.

Doi: 10.1016/j.jrp.2009.03.009

Levant, F. R. (1992). Toward the reconstruction of masculinity. Journal of Family Psychology, 5(3-4), 379-402.

Doi: 10.1037/0893-3200.5.3-4.379

Levant, F. R., Hall, J. R., Williams, M. C. ve Hasan, T. N. (2009). Gender differences in alexithymia. Psychology of Men and Masculinity, 10(3), 190-203.

Doi: $10.1037 / \mathrm{a} 0015652$

Leweke, F., Leichsenring, F., Kruse, J. ve Hermes, S. (2012). Is alexithymia associated with specific mental disorders? Pyschopathology, 45, 22-28. 
Doi: $10.1159 / 000325170$

Lopes, P. N., Brackett, M. A., Nezlek, J. B., Schütz, A., Sellin, I. ve Salovey, P. (2004). Emotional intelligence and social interaction. Personality and Social Psychology Bulletin, 30, 1018-1034.

Doi:10.1177/0146167204264762

Lumley, M. A. (2000). Alexithymia and negative emotional conditions. Journal of Psychosomatic Research, 49, 51-54.

Doi: 10.1016/S0022-3999(00)00161-6

Lundh, L. G., Johnsson, A., Sundqvist, K. ve Olsson, H. (2002). Alexithymia, memory of emotion, emotional awareness, and perfectionism. Emotion, 2(4), 361-379.

Doi: $10.1037 / 1528-3542.2 .4 .361$

Lundh, L. ve Simonsson-Sarnecki, M. (2001). Alexithymia, emotion and somatic complaints. Journal of Personality, 69(3), 483-510.

Doi: 10.1111/1467-6494.00153

Mattila, A. K., Ahola, K., Honkonen, T., Salminen, J. K., Huhtala, H. ve Joukamaa, M. (2007). Alexithymia and occupational burnout are strongly associated in working population. Journal of Psychosomatic Research, 62(6), 657-665.

Doi: $10.1016 / j . j p s y c h o r e s .2007 .01 .002$

Mesquita, B. (2001). Emotion in collectivist and individualist contexts. Journal of Personality and Social Psychology, 80(1), 68-74.

Doi:10.1037/0022-3514.80.1.68

Mikolajczak, M., Luminet, O. ve Menil, C. (2005). Predicting resistance to stress: Incremental validity of trait emotional intelligence over alexithymia and optimism. Psicothema, 18, 79-88.

Montes, G. ve Halterman, J. S. (2007). Psychological functioning and coping among mothers of children with autism: a population-based study. $\mathrm{Pe}$ diatrics, 119(5), 1040-1046.

Doi: $10.1542 /$ peds.2006-2819

Novick-Kline, P., Turk, C. L., Mennin, D. S., Hoyt, E. A. ve Gallager, C. L. (2005). Level of emotional awareness as a differentiating variable between individuals with and without generalized anxiety disorder. $\mathrm{Jo}_{0}$ urnal of Anxiety Disorders, 19(5), 557-572. 
Doi: 10.1016/j.janxdis.2004.06.001

Oelofsen, N. ve Richardson, P. (2006). Sense of coherence and parenting stress in mothers and fathers of preschool children with developmental disability. Journal of Intellectual and Developmental Disability, 31, 112.

Öksüz, Z. (2008). Otistik ve normal çocuk sahibi anne babaların bazı psikiyatrik ve psikolojik özelliklerinin karşılaştırılması. Yayınlanmamış yüksek lisans tezi, Marmara Üniversitesi Eğitim Bilimleri Enstitüsü Özel Eğitim Anabilim Dalı.

Paez, D., Seguel, A. M. ve Martinez-Sanchez, F. (2013). Incremental validity of alexithymia, emotional coping and humor style on happiness and psychological well-being. Journal of Happiness Study, 14(5), 16211637.

Doi: 10.1007/s10902-012-9400-0

Pavot, W. ve Diener, E. (2008). The satisfaction with life scale and the emerging construct of life satisfaction. The Journal of Positive Psycho$\log y, 3(2), 137-152$.

Doi: $10.1080 / 17439760701756946$

Pedrosa, G., Weigl, M., Wessels, T., Irnich, D., Baumüller, E. ve Winkelmann, A. (2008). Parental bonding and alexithymia in adults with fibromyalgia. Psychomatics, 49, 115-122.

Doi: 10.1176/appi.psy.49.2.115

Pennebaker, J. W. (1995). Emotion, disclosure, and health: An overview. J. W. Pennebaker, (Ed.), Emotion, disclosure, and health içinde (3-10). Washington, D.C.: American Psychological Association.

Doi: $10.1037 / 10182-015$

Piven J., Chase G. A., Landa R., Wzorek, M., Gayle, J., Cloud, D. ve Folstein, S. (1991). Psychiatric disorders in the parents of autistic individuals. Journal of the American Academy of Child \& Adolescent Psychiatry, 30(3), 471-478.

Doi: 10.1097/00004583-199105000-00019

Planalp, S. (1999). Communicating and emotion: Social, moral and cultural processes. Cambridge, UK: Cambridge University Press.

Rodriguez, C. M. ve Murphy, L. E. (1997). Parenting stres and abuse potential 
in mothers of children with developmental disabilities. Child Maltreatment, 3, 245-252.

Doi: $10.1177 / 1077559597002003006$

Ryff, C. D. ve Singer, B. (2008). Know thyself and become what you are: A eudaimonic approach to psychological well-being. Journal of Happiness Studies, 9, 13-39.

Salminen, J. K., Saarijärvi, S., Äärelä, E., Toikka, T. ve Kauhanen, J. (1999). Prevalence of alexithymia and its association with sociodemographic variables in the general population of Finland. Journal of Psychosomatic Research, 46(1), 75-82.

Doi: 10.1016/S0022-3999(98)00053-1

Sifneos, P. E. (1991). Affect, emotional conflict, and deficit: an overview. Psychotherapy and Psychosomatics, 56, 116-122.

Doi: 10.1159/000288543

Son, S. H., Jo, H., Rim, H. D., Kim, J. H., Kim, H. W., Bae, G. Y. ve Lee, S. J. (2012). A comparative study on alexithymia in depressive, somatoform, anxiety, and psychotic disorders among Koreans. Psychiatry Investigation, 9(4), 325-331.

Doi: $10.4306 /$ pi.2012.9.4.325

Stevens, J. C. (1992). Applied multivariate statistics for the social sciences. Hillsdale, NJ: Lawrence Erlbaum.

Szatmari, P., Georgiades, S., Duku, E., Zwaigenbaum, L., Goldberg, J. ve Bennett, T. (2008). Alexithymia in parents of children with autism spectrum disorder. Journal of Autism and Developmental Disorder, 38(10), 1859-1865.

Doi: 10.1007/s10803-008-0576-4

Tabachnick, B. G. ve Fidell, L. S. (2013). Using multivariate statistics (6. bask1). Boston: Pearson.

Taylor, G. J. (1994). The alexithymia construct: conceptualization, validation, and relationships with basic dimensions of personality. New Trends in Experimental \& Clinical Psychiatry, 10(2), 61-74.

Taylor, G. J., Bagby, R. M. ve Parker, J. D. A. (1997). Disorders of affect regulation: alexithymia in medical and psychiatric illness. Cambridge: Cambridge University Press. 
Telef, B. B. (2013). Psikolojik iyi oluş ölçeği: Türkçeye uyarlama, geçerlik ve güvenirlik çalışması. Hacettepe Üniversitesi Eğitim Fakültesi Dergisi, 28(3), 374-384.

Thimm, C. ve Lenelis, K. (1993). The power-emotion relationship in discourage spontaneous expression of emotions in asymmetric dialogue. $\mathrm{Jo}_{-}$ urnal of Language and Social Psychology, 12(1/2), 81-102.

Doi:10.1177/0261927X93121006

Tolmunen, T., Heliste, M., Lehto, S. M., Hintikka, J., Honkalampi, K. ve Kauhanen, J. (2011). Stability of alexithymia in the general population: An 11-year follow-up. Comprehensive Psychiatry, 52, 536-541.

Doi: 10.1016/j.comppsych.2010.09.007

Velasco, C., Fernandez, I., Paez, D. ve Campos, M. (2006). Perceived emotional inteligence, alexithymia, coping and emotional regulation. Psicothema, 18(1), 89-94.

Waller, E. ve Scheidt, C. E. (2004). Somatoform disorders as disorders of affect regulation: a study comparing the TAS-20 with non-self-report measures of alexithymia. Journal of Psychosomatic Research, 57(3), 239247.

Doi: 10.1016/S0022-3999(03)00613-5

Woolf, C., Muscara, F., Anderson, V. A. ve McCarty, M. C. (2016). Early traumatic stress responses in parents following a serious illness in their child: a systematic review. Journal of Clinical Pschology in Medical Setting, 23(1), 53-66.

Doi: 10.1007/s10880-015-9430-y

Wrana, C., Bruder, S., Thomas, W., Lane, R. D. ve Köhle, K. (2005). Emotional awareness deficits in inpatients of a psychosomatic ward: a comparison of two different measures of alexithymia. Psychosomatic Medicine, 67(3), 483-489.

Xiang, Y., Chi, X., Wu, H., Zeng, T, Chao, X., Zhang, P. ve Mo, L. (2017). The trauma of birth or parenting a child: Effect on parents' negative emotion in China. Archives of Psychiatric Nursing, 31, 211-216.

Doi: 10.1016/j.apnu.2016.10.001

Zaidman-Zait, A. ve Curle, D. (2015). Contextual action theory framework in counseling families of children with disabilities. R. Young, J. Domene 
ve L. Valach, (Ed.), Counseling and action içinde (239-253). New York: Springer.

Doi: 10.1007/978-1-4939-0773-1_14 